\title{
Carcinoma in situ conjuntival: reporte de un caso clínico
}

\author{
Jorge Luis Chin-Wong ${ }^{1, a}$
}

\section{RESUMEN}

El carcinoma in situ de conjuntiva forma parte de un grupo de entidades denominadas Neoplasias escamosas de la superficie ocular (NESO), que consisten en un amplio rango de lesiones corneoconjuntivales que abarcan desde displasias conjuntivales hasta carcinomas escamosos invasivos. De presentación rara, geográficamente son más frecuentes cerca de la línea ecuatorial y se asocian a diversos factores ambientales (exposición a rayos ultravioleta), infecciosos (Virus de papiloma humano, Virus de inmunodeficiencia humana), Carcinógenos químicos, entre otros. Presentamos el caso de un paciente con tumoración conjuntival diagnosticada inicialmente como pterigión por médico general, de crecimiento rápido, su manejo y su evolución.

Palabras clave: conjuntiva, carcinoma, neoplasia intraepitelial (Fuente: DeCS- BIREME)

\section{Conjunctival carcinoma in situ: a case report}

\section{ABSTRACT}

In situ conjunctival carcinoma is part of a group of entities called Ocular Surface squamous neoplasms (OSSN), which consist of a wide range of cornea-conjunctival lesions ranging from conjunctival dysplasia to invasive squamous carcinomas. Rare presentation, geographically they are more frequent near the equator and are associated with various environmental (exposure to ultraviolet rays), infectious (human papillomavirus, human immunodeficiency virus), chemical carcinogens, among other factors. We present the case of a patient with a rapid growth conjunctival tumor, its management and its evolution.

Keywords: conjunctiva, carcinoma, intraepithelial neoplasm (Source: MeSH - NLM)

\footnotetext{
${ }^{1}$ Servicio de Oftalmología, Hospital Regional Lambayeque, Chiclayo, Perú.

a Médico oftalmólogo.
} 


\section{INTRODUCCIÓN}

Las neoplasias escamosas de la superficie ocular (NESO) engloban un grupo de patologías que incluye a la displasia, carcinoma in situ y carcinoma epidermoide de la conjuntiva (1). Es el tumor no pigmentado conjuntival más frecuente, con una incidencia de 0,03 a 1,9 casos por 100000 personas por año en población caucásica (2), y de 3 a 3,4 casos por cada 100000 personas por año en población africana (3). De incidencia rara, casi nunca hacen metástasis pero causan destrucción tisular importante con pérdida de la función, alteración anatómica o pérdida del globo ocular afectado y sus anexos.

Es importante siempre tenerlo en cuenta para el diagnóstico diferencial de patologías conjuntivales consideradas benignas como el pterigión y pingüeculas que afectan la misma región anatómica y que pueden llevar a un diagnóstico y manejo inadecuados, con la consecuente progresión y extensión de la lesión.

Presentamos el caso clínico de un paciente manejado inicialmente por médico general en periferia, discutimos el manejo médico quirúrgico y la evolución postoperatoria a un año de seguimiento.

\section{REPORTE DE CASO}

Paciente femenino de 41 años de edad, sin antecedentes personales patológicos ni quirúrgicos de importancia, se presenta a consulta externa con "carnosidad" de crecimiento lento en el ojo derecho, disminución de la agudeza visual, hiperemia conjuntival, lagrimeo y sensación de cuerpo extraño; con un tiempo de evolución de dos meses, durante los cuales ha recibido lubricantes tópicos (indicados por médico general) con remisión parcial de los síntomas.

Al examen físico del ojo derecho se encuentra una agudeza visual de 20/100 que no mejora con refracción, y una presión intraocular de $14 \mathrm{mmHg}$. En segmento anterior se encuentra tumoración pediculada móvil de aspecto rugoso-gelatinoso en región limboescleral nasal de aproximadamente $8 \times 6 \mathrm{~mm}$, con hiperemia conjuntival perilesional, vasos nutricios e involucro corneal de aproximadamente $3 \mathrm{~mm}$ (figura 1 y 2). El examen de fondo de ojo fue normal. El examen físico del ojo izquierdo tuvo una agudeza visual de 20/25 que mejoró a 20/20 con anteojos, y su presión intraocular de $14 \mathrm{mmHg}$. La exploración de segmento anterior y posterior es normal.

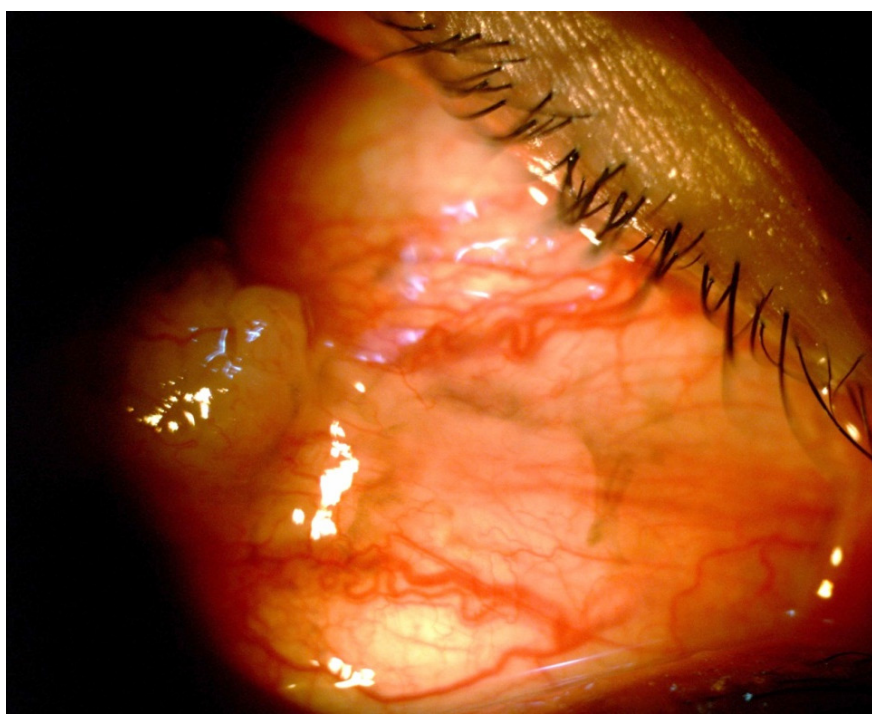

Figura 1. Lesión de aspecto nodular y gelatinoso, móvil e indoloro en la región inter palpebral nasal de ojo derecho, con vasos nutricios que cubre parte de la córnea.

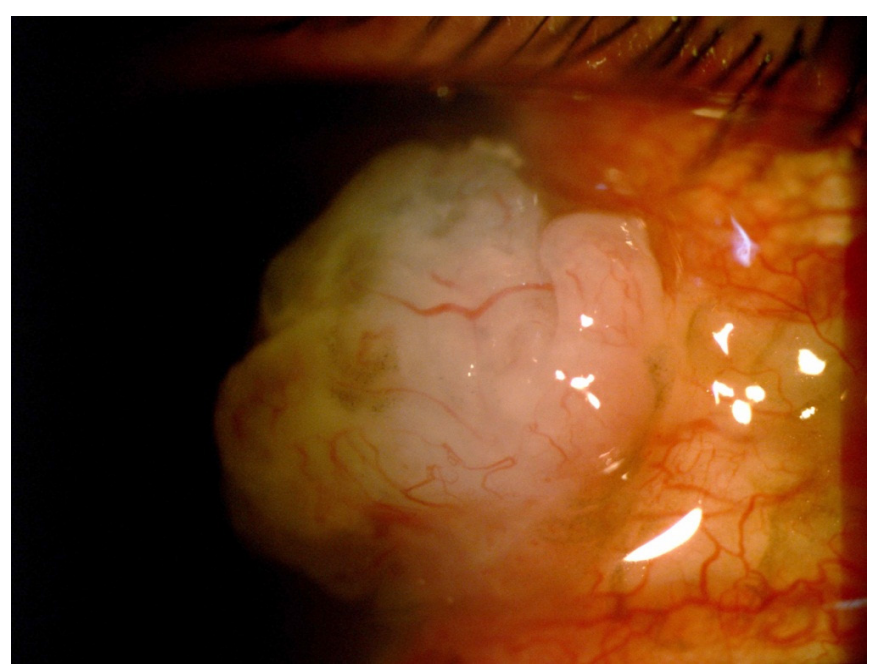

Figura 2. Vista ampliada de la lesión.

Por las características inusuales del tejido tumoral, presencia de vasos nutricios evidentes, y aspecto gelatinoso-pediculado, se realizó diagnóstico presuntivo de carcinoma in situ conjuntival en ojo derecho y se programa para biopsia excisional. Se realizaron estudios preoperatorios de rutina y examen serológico para HIV con resultado negativo.

La biopsia excisional del tumor se realizó mediante técnica 
de "no contacto", usando anestesia tópica con proparacaína $0,5 \%$ y dilatación pupilar, más vasoconstricción local con gotas de fenilefrina $5 \%+$ tropicamida $0,5 \%$.

Se realizó liberación de los bordes conjuntivales con un margen de seguridad de $4 \mathrm{~mm}$ y cauterización de vasos. Luego se aplicó alcohol $96^{\circ}$ durante un minuto en área corneal involucrada, con posterior desepitelización mecánica respetando los márgenes de seguridad mencionados. Se retiró el tumor con disección cuidadosa del pedículo limbal con una esclerectomía laminar en su base empleando cuchillete Crescent. En ningún momento se manipuló directamente el tumor. Posteriormente se aplicó Mitomicina C (MMC) 0,02 \% sobre el área durante dos minutos y se procede a irrigación copiosa con solución salina balanceada. Se finaliza con injerto de membrana amniótica fijada con puntos de Nylon 10/0 separados. El tejido extraído se envió a estudio anatomopatológico que reveló el diagnóstico de neoplasia intraepitelial escamosa 'de alto grado (carcinoma in situ).

La evolución postoperatoria inmediata fue satisfactoria, se empleó tratamiento tópico compuesto con tobramicina 0,3 $\%$, dexametasona 0,1 y tetrahidrozolina $0,025 \%$, cada 6 horas por 10 días; y ácido hialurónico 0,4 \% tópico cada dos horas. Se retiraron, sin complicaciones, los puntos al décimo día e inició con dos cursos de MMC 0,02 \% tópico por 15 días cada 6 horas, separados 15 días uno del otro (figura 3).

Un año después la evolución clínica es favorable: se encuentra asintomática y el examen físico del ojo operado muestra agudeza visual en 20/25 que mejora a 20/20 con corrección. Se observó leucoma corneal avascular nasal correspondiente al área afectada por la tumoración, conjuntiva de aspecto normal, sin apreciarse recurrencia de la lesión. El examen de fondo de ojo no mostró alteraciones (figura 4).

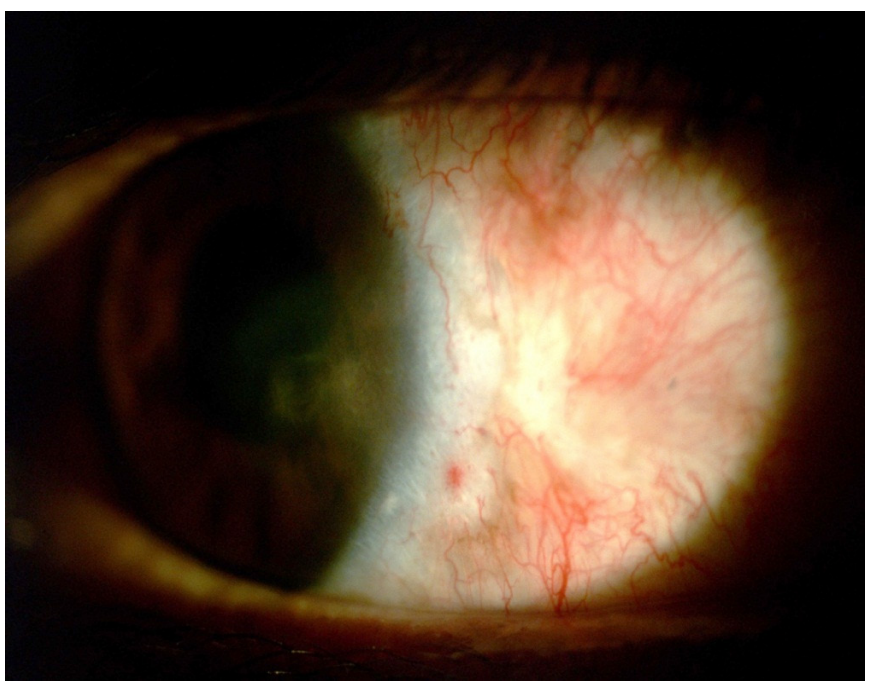

Figura 3. Postoperatorio una semana después de inicio de terapia con Mitomicina $0,02 \%$ tópico

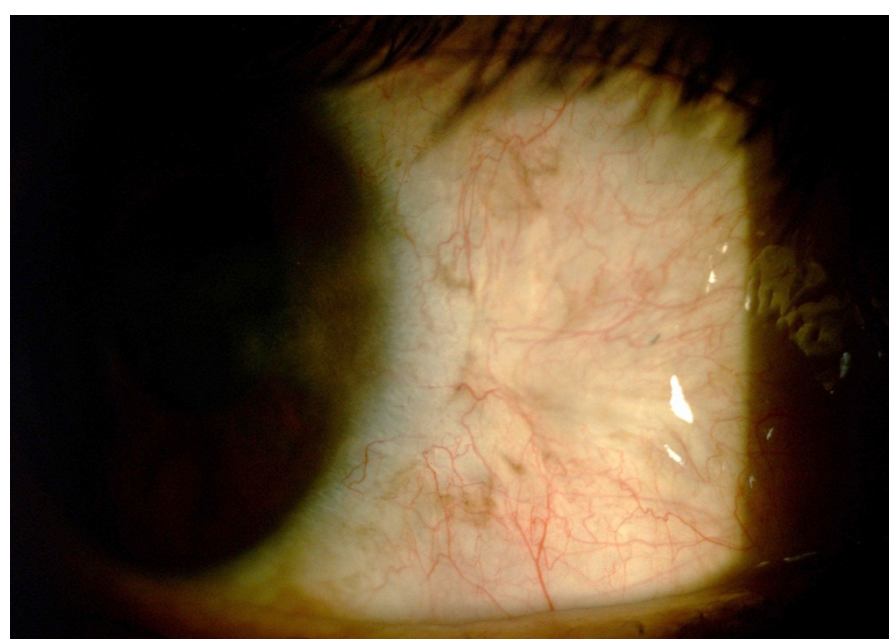

Figura 3. Postoperatorio un año después de la cirugía.

\section{DISCUSIÓN}

Las neoplasias escamosas de la superficie ocular (NESO) en sus fases iniciales pueden ser sub diagnosticadas o ser confundidas con patologías degenerativas de la conjuntiva como los pterigiones o pingüéculas, con el consecuente retraso del diagnóstico y mayor infiltración a medida que pasa el tiempo. Es importante conocer que existe una incidencia de NESO no sospechada en reportes de patología de muestras diagnosticadas clínicamente de pterigión que varía de $0,65 \%$ a $1,8 \%$ por lo que es importante remitir al especialista a los pacientes que presentan alguna lesión sospechosa (4).

El principal factor etiológico relacionado es la exposición a la radiación ultravioleta, con el consecuente daño a los mecanismos de reparación del ADN y también causando mutación en el gen p53 ${ }^{\left.{ }^{5}\right)}$. La enfermedad es más probable en el sexo masculino y una edad promedio entre la sexta y séptima década de la vida. El caso clínico presentado difiere de esta tendencia. Cuando se presentan en edades más tempranas, se pueden asociar a la presencia de otras patologías de importancia.

Se ha considerado la relación entre esta patología en pacientes con diagnóstico de xeroderma pigmentosa, papiloma virus humano tipo 16 ó 18, o infección por virus de la inmunodeficiencia humana (VIH), en edades más tempranas (6), por lo que en pacientes jóvenes con NESO es importante descartar infección por VIH porque presentan cuadros más agresivos e invasivos que pueden requerir incluso enucleación o excentración del globo ocular.

La presentación clínica suele ser en la región inter palpebral cercana al limbo esclerocorneal, involucrando principalmente la conjuntiva bulbar y en menor frecuencia, la conjuntiva tarsal. Los bordes pueden ser bien delimitados y existe la presencia de vasos nutricios. Presenta síntomas y signos de irritación ocular como ojo rojo, sensación de cuerpo extraño y a veces disminución de la agudeza visual asociada a un 
astigmatismo secundario a la lesión, o al bloqueo del eje visual por el tumor. Morfológicamente se describen tres tipos: gelatinoso (leucopláquico o papiliforme) es el más común, nodular (masa elevada con aspecto de "mora") y variante difusa (crecimiento predominantemente en extensión, con bordes mal definidos) (6,7) .

El paciente del caso clínico presentado tenía 41 años de edad al momento del diagnóstico y tuvo una evolución clínica rápida (dos meses), de una lesión de tipo gelatinosa-papiliforme en región interpalpebral nasal de ojo derecho. Se realizó el descarte de $\mathrm{VIH}$, ya que los cuadros clínicos asociados a esta infección son de inicio más temprano y de curso más agresivo. Las NESO son la primera manifestación de VIH/SIDA en 26 a $86 \%$ de casos y son seropositivos a $\mathrm{VIH}$ entre 38 a $92 \%$ de pacientes con NESO (8). El resultado en este caso fue negativo.

El manejo convencional de esta enfermedad ha sido el abordaje quirúrgico. La técnica de no contacto ("no touch") descrita por Karp y Gupta (9), tiene como finalidad evitar la diseminación de células cancerosas a los tejidos adyacentes evitando manipulación innecesaria del tumor. Sin embargo, cada vez se emplea con mayor frecuencia quimioterapia tópica o intralesional con interferón alfa (IFN- $\alpha 2 b)$, Mitomicina C (MMC) 0,02 \% y 5-Fluorouracilo (5-FU) en combinación o no con la excisión quirúrgica. En este caso realizamos un manejo combinado debido a la extensión de la lesión y a las características de la paciente. La evolución postoperatoria a un año de la cirugía es satisfactoria, sin recurrencia ni sintomatología.

En conclusión, las patologías conjuntivales más frecuentes como pterigión y pingüecula pueden ser confundidos con los estadios iniciales de enfermedades potencialmente peligrosas para la integridad anatómica y funcional del globo ocular, por lo que importante referirlos al oftalmólogo para su correcto diagnóstico, apoyados en un estudio anatomopatológico, y tratamiento adecuado. A los pacientes jóvenes que presentan esta patología se debe descartar la presencia de HIV, dada la naturaleza agresiva y destructiva de la tumoración en este grupo de pacientes. En este caso, la biopsia excisional y el tratamiento tópico con MMC 0,02\% en dos cursos de 15 días, separados por 15 días entre ellos, fue eficaz. La agudeza visual mejoró y no se ha presentado recurrencia a un año después del procedimiento.

Conflicto de interés: el autor declara no tener conflictos de interés.

Fuentes de financiamiento: autofinanciado.

\section{REFERENCIAS BIBLIOGRÁFICAS}

1. Lee GA, Hirst LW. Ocular surface squamous neoplasia. Surv Ophthalmol 1995; 39:429-450
2. Lee GA, Hirst LW. Incidence of ocular surface epithelial dysplasia in metropolitan Brisbane. A 10-year survey. Arch Ophthalmol. 1992;110(4):525-7

3. Furahini G, Lewallen S. Epidemiology and management of ocular surface squamous neoplasia in Tanzania. Ophthalmic Epidemiol. 2010 17(3):171-6.

4. Furuya L, Dulanto C, Stone J, Marroquín L, Dulanto V, Roca J, Contreras F, Lee G. Neoplasia escamosa de la superficie ocular en pacientes con pterigión en Perú. Indian J Ophthalmol. 2015; 63(8):672-4.

5. Mahomed A, Chetty $R$ Human immunodeficiency virus infection, 18 $\mathrm{Bcl}-2$, p53 protein, and Ki-67 analysis in OSSN. Arch Ophthalmol 2002; 120:554-8.

6. Gichuhi S, Sagoo MS, Weiss HA, Burton MJ. Epidemiology of ocular surface squamous neoplasia in Africa. Trop Med Int Health. 2013;18(12):1424-43

7. Gichuhi S, Macharia E, Kabiru J, et al. Clinical presentation of ocular surface squamous neoplasia in Kenya. JAMA Ophthalmol. 2015; 133(11):1305-1313.

8. Gupta S, Ganguly A, Kaliki S. Ocular surface squamous neoplasia in HIV-infected patients: current perspectives. HIV AIDS. 2018; 10: 33-45.

9. Michael Tsatsos; Carol L Karp. Modern Management of Ocular Surface Squamous Neoplasia. Expert Rev Ophthalmol. 2013; 8(3):287-295.

Revisión de pares: Recibido: 15/05/2019 Aceptado: 25/06/2019 